\title{
14 Perception of mobility poverty in remote peri-urban Salento, Italy
}

\author{
Cosimo Chiffi, Silvia Maffii \\ and Patrizia Malgieri
}

\begin{abstract}
This chapter provides a description of fieldwork activities carried out in a community of 14 small towns located in the extreme south east of Italy. This remote, peri-urban territory is included in an Italian national development programme aimed at reversing the depopulation and economic decline of more marginalised "inner areas". The research focused primarily on the mobility needs of women and people with reduced mobility. Interviews and focus groups demonstrated a high level of awareness around current mobility poverty's conditions as well as the knowledge and reclamation of more inclusive and flexible collective transport to allow personal mobility mainly on shorter routes and thus enrich living conditions within the area.
\end{abstract}

\section{Introduction}

The Cape of Leuca in the Salento peninsula is the most south-eastern part of Italy's boot in the region of Apulia. It is one of the many finisterrae of the European continent classified as a "remote area" by the Italian National Strategy for Inner Areas (SNAI), a cohesion and development programme addressed at territories distant from centres offering essential services and characterised by the phenomena of depopulation and degradation.

The "Inner Area of Southern Salento - Cape of Leuca" is an association of 14 small towns in the Province of Lecce (Acquarica del Capo, Alessano, Castrignano del Capo, Corsano, Gagliano del Capo, Miggiano, Montesano Salentino, Morciano di Leuca, Patù, Presicce, Taurisano, Salve, Specchia and Tiggiano) that has recently been included in the aforementioned programme with the adoption of an action plan aimed at reversing declining socio-economic trends. Four additional municipalities (Tricase, Ruffano, Casarano and Ugento) are part of the wider "strategy area" being the nearest service centres of the towns in the Cape (Figures 14.1).

This almost totally flat land is a polycentric scattered area characterised by the presence of numerous compact historical towns and just a few rural settlements. It can be classified as remote peri-urban with the presence of 


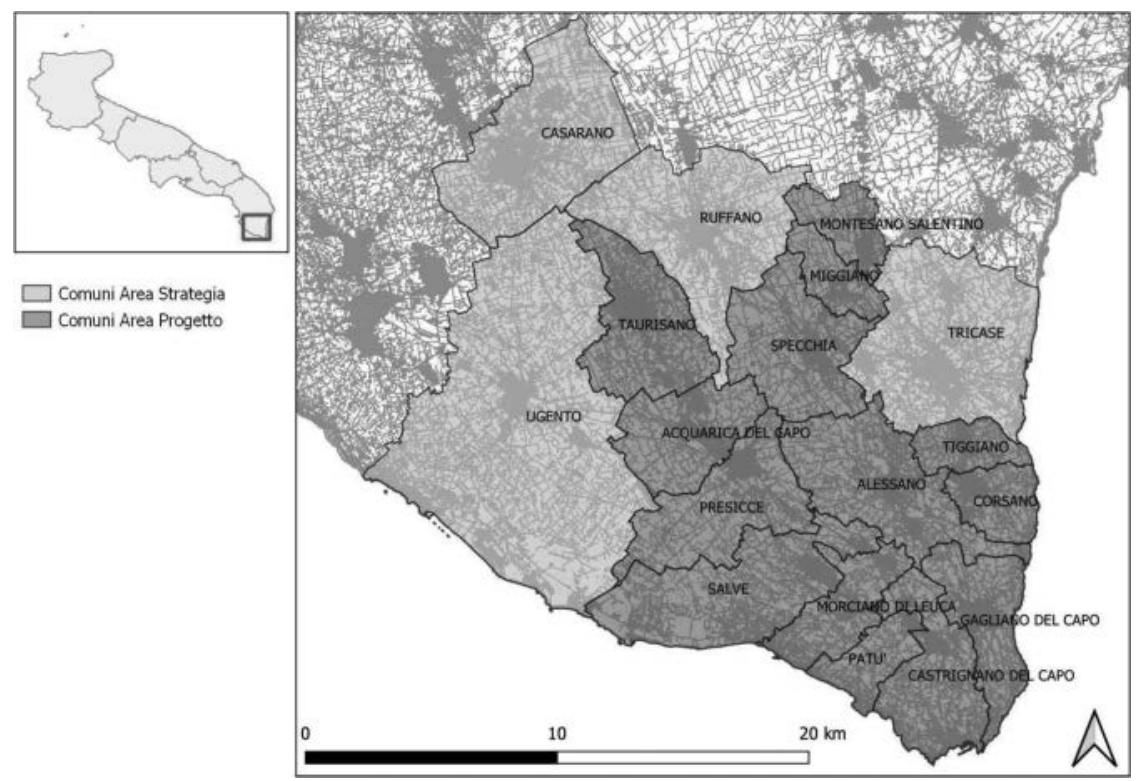

Figure 14.1 Italian Inner Areas and perimeter of the strategy area of Southern Salento - Cape of Leuca.

Source: Regione Puglia - Area Interna Sud Salento 2018.

coastal marinas, inner towns and rural farms in the countryside. Built-up areas are concentrated around town centres and the average population density is 275 inhabitants per square $\mathrm{km}$, in line with both provincial and regional values. In terms of spatial characteristics, Southern Salento therefore constitutes more of a common rather than a peculiar peri-urban area in Apulia (Istituto Nazionale di Statistica 2018a).

A total of 67,775 inhabitants live in the inner area distributed in little towns and hamlets each with a total population between 1,000 and 5,000 residents. In terms of residents, the number almost doubles in the four nearest service centres. The number of residents in the inner area decreased by $0.6 \%$ between 2001 and 2011, a trend that accelerated between 2011 and 2017 with the loss of 2,176 inhabitants in parallel with a sharp increase in the ageing index: the ratio between those over 65 and those aged $0-14$ is one of the highest in Italy ranging from 300 to 190 for the majority of the inner area towns (Istituto Nazionale di Statistica 2018a).

The Italian National Statistics Institute (ISTAT) includes the area of Southern Salento in the territories with a high risk and medium-high risk of social and material vulnerability rates (Istituto Nazionale di Statistica 2018b). It shows a very high rate of unemployment especially among women 
(16\% to $31 \%$ across the 14 towns) and young people (23\% to $52 \%)$ and a high share of elderly people living alone (22\% to $30 \%)$.

The main manufacturing sector used to be what is known as the TAC district of textile, clothing and shoe industries. However, due to competition from other countries with lower labour costs, it almost disappeared and many companies and jobs were lost in the last 15 years. The monoculture of olive trees has recently been infected by the bacterium Xylella fastidiosa, a pathogen that is devastating to the landscape of Salento with severe impacts on the production of olive oil and the agricultural sector as a whole. The area is also becoming a fast-growing tourism destination with seasonal employment opportunities increasing during the summer period even if this has not counterbalanced the loss of workplaces due to the decline in manufacturing (Capestro et al. 2014).

In terms of spatial hierarchy, the city of Lecce is the closest centre to access main public offices, its university, larger employers, main events and cultural places. Inner area towns and hamlets in Southern Salento mostly belong to the main service centres of Tricase (17,000 inhabitants) and Casarano (20,000 inhabitants), where local hospitals, high schools and cinemas are located. Within the area, the towns of Alessano and Castrignano del Capo, close to the Cape, host some high schools and medical clinics. Average distances to reach basic services range between 10 and $15 \mathrm{~km}$ from each town whereas workplaces are more sparsely located throughout the territory and not concentrated in a few poles.

\section{Transport characteristics in Southern Salento}

The Salento peninsula is far away from national motorways which only have connections in Bari or Taranto, over $200 \mathrm{~km}$ and $180 \mathrm{~km}$ distant from the Cape of Leuca, respectively. However, the area is connected to these regional nodes by two main state road corridors also crossing the international airport and seaport of Brindisi (120 km away) and the provincial capital of Lecce ( $80 \mathrm{~km}$ away, or 70 minutes by car). Lecce is also the terminus of the national railway network. Rail corridors linking Salento to Rome and to northern Italian cities along the Adriatic line still suffer from a lack of services and some infrastructure bottlenecks, with no high-speed rail connections. The absence of faster long-distance trains and the peripheral location of the inner area therefore results in higher interconnection costs with vast and distant markets that have only been partly reduced due to recent investment and the growth of the airport in Brindisi.

The road network of the whole of Salento is more characterised by smallscale diffused infrastructures that include provincial, municipal and rural roads plus the capillary railway network of Ferrovie del Sud Est (FSE). Built in the second half of the 19th century, this state-owned non-electrified local railway has experienced a gradual lack of upgrading and maintenance of its 
tracks, station buildings and rolling stock in the last decades. The absence of proper safety systems resulted in a maximum permitted speed of only 50 km/h (Agenzia Nazionale per la Sicurezza Ferroviaria 2016) ${ }^{1}$ making travel times very long on almost every connection and a load factor below $15 \%$. In 2016, due to financial and judiciary problems experienced by the company, the network was taken over by the Italian railways (Gruppo Ferrovie dello Stato Italiane - FSI) and a big renovation programme has finally started. The FSE network is therefore in a transition phase with several projects, including its electrification, currently ongoing (FS News 2019).

The local bus network is not optimised nor adapted to the dispersed territorial context with many overlapping bus lines (served by a fragmented range of different companies), no demand-responsive services being operated in combination with PT corridors and existing services targeted principally at home-to-school trips. Most towns in the province of Lecce are served by just two bus journeys per day and only during the summer period does a seasonal bus service called Salentoinbus with higher frequency provide public transport accessibility to the towns and coast in order to support the tourism industry.

Due to the low mobility demand, but also the poor quality of public transport services, many commuting trips in Southern Salento are made by private motorised transport: 61-66 per 100 inhabitants according to 2011 Census data in the different towns. This has also been confirmed by a recent mobility survey carried out at regional level (ASSET Regione Puglia 2019).

The motorisation rate of 57.7 cars per 100 inhabitants in the inner area is a bit lower than the national average (62 cars/100 inhabitants), but higher than Apulia's regional rate (54 cars/100 inhabitants) (Automobile Club d'Italia 2018).

\section{Interviews with local actors and stakeholders}

The social groups primarily targeted by the fieldwork, conducted in 2018 and 2019, were women and people with reduced mobility. ${ }^{2}$ In preparation of the focus groups with citizens, several key stakeholders have been interviewed, ranging from educational and social institutions to civil society associations, from local politicians to transport suppliers' representatives. This offered some insights into the local context and the mobility situations with which the two vulnerable categories have to contend every day, allowing an initial understanding of the mobility system as a whole (intercepting problems also affecting other social groups, particularly the elderly and young people).

Women's mobility-related situations and mobility needs have been discussed with the representatives of Le Costantine, a local foundation providing training and working opportunities for women in biodynamic agriculture and handmade weaving (but also running a Steiner school and 
educational centre for young people). We met Serenella Molendini, currently Deputy National Advisor on Gender Equality (and formerly advisor of the Puglia Region and the Province of Lecce) as well as the social cooperative Comunità di San Francesco that runs the local anti-violence network. The Comunità di San Francesco also offers social and educational services to elderly people, children, families and people with disabilities (which is also of interest to the second focus group).

In order to understand the mobility needs and available transport options for citizens with reduced mobility, the project interviewed officers at the Local Health Service ASL, the University of Lecce and the operators of Terra Rossa, a social cooperative working in both physical and cognitive accessibility. In addition, for both vulnerable groups, the footwear manufacturer Calzaturificio Sud Salento (a big employer in the inner area with 250 workers), the railway company Ferrovie del Sud Est and some mayors have also been involved in order to include the points of view and perceptions of mobility poverty conditions in the area by some key actors and policy makers.

\section{Main outcomes of the interviews}

The overall perception among the stakeholders not providing transport services and the politicians is that the local collective mobility system is almost "non-existent, inefficient and of very poor quality". They identify mobility as a crucial issue because it cuts across different parameters such as access to work, education and leisure opportunities for inner area residents. With reference to the two vulnerable social groups, they underlined the impacts of the mobility system on family care and independence, allowing or preventing a work-life balance both for women and for families who need to assist a person with reduced mobility.

The remoteness and peri-urban characteristics of the area are ambivalent. On the one hand, they mean longer commuting trips to reach Lecce and other larger service centres; on the other hand, they demand more frequent, often shorter trip chains (particularly for women) between two or more towns to access facilities for children, the elderly and disabled care as well as social activities. For longer distances, there is no alternative to the private car, with the rail service still being too slow (as mentioned earlier), while the bus network is mostly organised around the needs of public schools (but not other training and educational centres), only offering morning journeys.

In Puglia, we have one of the most advanced legislation and policy frameworks addressing the needs and well-being of families - argued Serenella Molendini. The whole system of social services - from kindergartens to socio-educational centres for disabled minors - has been restructured with more diversified and high standard facilities that are now also closer to people and towns. 
These structures are fundamental especially in an area where work resignations following maternity leave are still too high and unfortunately not declining. The gender equality advisor pointed out the efforts made using the so-called Piani dei Tempi e degli Spazi (Territorial Time and Site Plans), a tool for analysing and planning physical accessibility and coordinating opening/closing times for certain services and activities in order to meet family (i.e. often women's) needs and work constraints. This tool was very useful for the acquisition of knowledge on mobility poverty conditions in the region, but unfortunately led to no implementation nor adaptation of services in order to fill the gaps:

There are no virtuous examples of mobility services that have joined the new reorganisation of family care services so the transport barrier remained unsolved. Especially in small towns, the hourly flexibility of workplaces and public services is not as important as the public transport links with neighbouring towns and with larger municipalities, which are almost nonexistent.

added Molendini

This situation was also confirmed by the stakeholders offering educational and training opportunities for the communities of Southern Salento. They are often forced to organise door-to-door minibus services themselves, thus reducing the budget for other courses or the number of participants. Commuting trips to reach workplaces are often self-organised with informal carpooling teams by the employees. In this respect, these bottom-up actions are an answer to very poor mobility options and they can also be a foundation for future activities.

Special needs transport for primary school pupils is organised directly by the municipalities, whereas secondary school students with reduced mobility can use dedicated services (established by the Province of Lecce). The University of Salento also has a dedicated minibus, but such a service can only offer one return trip per week due to the limited coverage and capacity of the service, particularly for longer distances. The person in charge of the Integration Office at the University of Salento, Paola Martino, underlined the fact that

every attempt to coordinate the available public transport offer failed in the past because, despite the limited but rising number of buses equipped with ramps for wheelchairs, the operators are not able to guarantee their usage on a certain line or ride.

This is mostly because vehicles are assigned to services according to drivers' shifts and not to lines, thus failing to guarantee a proper accessibility and quality standard. The Public Health Service ASL provides special transport services throughout the whole province with 18 equipped minibuses 
allowing people with reduced mobility and disabilities to reach hospitals, rehabilitation services, mental health and socio-educational centres. Despite the availability of the vehicles, as well as the coverage of a large part of both fixed and running costs associated with the service, these minibuses cannot be used for any other travel purposes.

\section{Focus groups in the inner area of Southern Salento}

The fieldwork activity in Southern Salento ran two focus groups, with parallel and plenary sessions, devoted to vulnerable group categories. These were held in the small town of Patù (1,700 inhabitants) and in the main city of Tricase. In total, 17 women and 28 people with reduced mobility took part in the two events. The second group constituted, for the most part, people with permanent reduced mobility, but also elderly people with walking difficulties and a woman with a broken leg. Parents and representatives of local associations for disabled people were also present.

The involvement and participation efforts of people in wheelchairs were particularly challenging: they heavily rely on the availability of their parents and relatives to chauffeur them by car. Preliminary contacts by phone revealed the need for many of them to establish a very precise agenda for their daily and occasional mobility needs in advance, depending on the agendas of their relatives and friends. A dedicated special transport service to reach the venues was therefore also offered by the focus group's conveners, but only one participant chose this solution. Others initially asked about the presence of a professional assistant but in the end preferred to use the more familiar option of being supported by relatives and friends. Two invited disabled participants cancelled their attendance due to last minute changes in the availability of their relatives. Participants based in the village of Patù came with their own motorised wheelchairs; one disabled participant drove his own specially equipped car.

At both events, people with reduced mobility were quite heterogeneous in terms of age, working situation and level of autonomy. This heterogeneity was less marked in the two focus groups of women: most of them were employed or self-employed and married, though from different generations. In both focus groups, the level of attention and participation was particularly high. Women's focus groups actively debated topics such as access to work and education, family care, personal fulfilment and more generally the socalled "work-life balance", that is, the difficulties in coordinating work and personal life.

Focus groups were carried out following a participatory method inspired by GOPP (Goal Oriented Project Planning) according to an established approach: the emergence of problems (first discussion), definition of problems (by using sticky notes) and clustering of problems. A white message board with the title "Which mobility problems do you face in your daily life?" was used to structure the discussion. Within their focus group, the two 
categories of vulnerable users have been able to identify and define heterogeneous problems related to their mobility experiences as described below.

\section{Women's travel requirements, mobility poverty and social exclusion}

When discussing women's mobility problems in Southern Salento, the first issue raised by the participants was naturally the absence of proper public transport options. This was seen as one of the main barriers affecting women's capability of moving around, preventing them from being autonomous and making them more prone to social isolation. Without owning a car, many places in the whole province are in fact considered inaccessible.

Immigrant women in particular who need to reach local health services or who are users of the anti-violence centre in Ugento are highly affected, as attested by two female workers participating in the focus group. Indeed, a second car is not available in every family and the one the family owns is mostly used by the male adult. However, women who can use their own car also expressed dissatisfaction: cars can be a convenient means of transport, but the participants reported that they were "forced" to use (and overuse) private motor vehicles. In both focus groups, participants asked not only for an improvement of the public transport options (e.g. more frequent and faster trains or express buses to reach destinations further away), but immediately identified more flexible, on-demand minibus services as the most appropriate solution for travel within the inner area. This was somewhat surprising to the facilitators, considering this type of service is not present in the region. On different occasions, they declared their willingness to also use commercial ride-hailing options if available:

I use the car for both commuting to work and for leisure. I would definitely prefer to use it less. Now that my leg is broken, I'm constantly dependent on someone else from my family and this is a total waste of time for them. A call-a-bus service with minibuses would be ideal.

Women struggle to coordinate trips to accomplish work, family and leisure activities with men usually providing very little support. A lot of time has to be invested to satisfy all these mobility needs and to cross and reach towns that are relatively close to each other. Also, as stated by one focus group member, "if you drive a lot for work purposes and for family reasons, you tend to avoid additional car trips for leisure and social activities (i.e. to meet friends)".

Another issue that greatly affects women is their limited number of opportunities in terms of jobs and higher/professional education, which often require a long commute such as to reach the city of Lecce. The absence of proper public transport can seriously compromise women's future job and training opportunities and personal growth. Safety and security issues are 
always a concern for women in transportation due to poor road and signage conditions as well as due to the absence of proper lighting that create difficulties in driving across towns or along secondary roads. In addition, the absence of police checks contributes to the creation of a sense of danger as does the lack of public transport options that force young people to use private cars, fostering anxiety, stress and concern among mothers.

\section{People with reduced mobility needs, mobility poverty and social exclusion}

For this category, the absence of accessible public transport alternatives or dedicated mobility services was quite immediately identified as the main element affecting people with reduced mobility autonomy and social life. They also indicated the absence in the area of a special taxi/equipped hire car with driver services (only one local entrepreneur offers such a service!), pointing out how a similar system addressed tourist's needs in the summer season. It was also reported that most buses and trains are not equipped with lift platforms making them therefore inaccessible to people in a wheelchair. Public transit personnel are neither adequately trained to assist them (e.g. some do not know how to lift the platforms) nor to provide travel information. Any information acquired is simply confusing and unclear.

This lack of coordination and reliable information hamper mobility, especially when the trips are made in two or more parts: "if from my town I have to get to Lecce and I have to change bus or operator on the way, then I am not sure I can access the second vehicle because accessibility standards are not guaranteed". Public transport services are thus perceived as inadequate. Quite often public transport facilities are planned without considering the requirements of persons with a disability and, even when the equipped vehicles exist, quite often stations and bus stops are not accessible. Services and equipment cannot be used independently and without assistance, which is also a barrier.

The overall perception is that public institutions are not sensitive towards the basic needs of people with reduced mobility: "The disabled person seems to be a burden for the municipal administration" There is no monitoring and evaluation of the accessibility requirements of city services, buildings and especially transport infrastructures: many municipalities have not adopted the PEBA (Plan for the elimination of accessibility barriers), nor nominated a representative to defend the rights of disabled people. Many focus group participants declared they would be available to take up this role.

Universal design principles and accessible public transport solutions were well known among the participants as well as their potential benefit for the whole community: "In some cases, there is a lack of adequate knowledge from the municipal administration. Some services may also be 
useful for other categories of users". "In many European cities, there are integrated services that are good for all citizens even with beautiful aesthetic solutions and the staff in these cities receive comprehensive training."

Additionally, leisure facilities (like beaches and festival venues) are not accessible to such vulnerable users: available services are not provided for these events, which de facto excludes them from public activities and society at large. To compensate for these disadvantages, both local associations very often provide mobility services on a volunteer basis and for free.

When dealing with the use of private cars, both as a passenger or driver, the absence of dedicated parking spaces is perceived by users as a key barrier even to travel within the same town: "Finding a car park is a utopia in my town. I stopped using the car, I prefer to go around in my wheelchair, but I encounter many architectural barriers". Car parks are not only located too far away from the final destination, they are also inaccessible, as no proper attention is paid to basic design elements. These facilities are designed with insufficient space to allow a disabled passenger to get out of a car, with assistance from another person or by themselves, and frequently these spaces are used by non-authorised drivers, with no enforcement to prevent illegal parking.

An important aspect that emerged from the discussion is that people with reduced mobility focus on door-to-door accessibility. For them, infrastructures and means of transport are all part of the same "problematic" system: whatever the barrier, the impact is reduced mobility, irrespective of whether it is an interrupted pavement, lack of parking space, absence of equipped vehicles or absence of ramps. Such a systemic and inclusive approach offers us important insights.

\section{Conclusions}

Sustainable mobility and - in particular - public transport have not been at the top of political agendas for many years. The remoteness of Southern Salento and its large dependency on private transport only recently prompted local policy makers to focus on the topic. The main outcome has been the "Inner Area Strategy" report, which focuses primarily on the topic of sustainable mobility. We can find some signs of a paradigm shift: gradually, the political debate is moving away from the subsidising of improvements and investments in road infrastructure (including additional high-capacity state roads) to a higher level of service in collective public transport. The role of local railway and a more coordinated and efficient bus and rail network is getting more attention such as innovative solutions like flexible on-demand minibus services. These new approaches appear to be in line with the perceived needs of local communities. Even if no tangible changes are visible so far, investments and public funds for the implementation of these new plans have been secured by the Inner Areas National Committee and the Apulia Regional government. 
We also noticed a lack of appropriate knowledge about the term and meaning of mobility poverty, although almost all interviewees and focus group discussions recognised the issue. Overall, the current public transport system largely inhibits the possibility of accessing public services, social facilities as well as job/professional and leisure opportunities for the two social categories investigated as well as other vulnerable groups like the young and elderly people or immigrants without a car.

The fieldwork activities in Southern Salento show that in a remote rural and peri-urban territory, in addition to faster and more efficient opportunities to link with far away destinations, communities are requesting more sustainable and flexible local collective transport services, those allowing mobility on shorter routes in order to enrich living conditions within the area. In this regard, coherent and coordinated transport service design and inclusive mobility are seen by both focus groups' participants as important tools, having the potential to improve significantly the mobility of vulnerable groups. We also found an acceptance of moving away from personalised (and thus limited and expensive) services towards integrated solutions, suitable for a large pool of users and their needs. Interviewees and focus groups' participants were confident that these innovative services will also positively impact other vulnerable groups like the elderly, children and young people and immigrants.

\section{Notes}

1 This is a national restriction issued by the Italian railways safety agency ANSF (Agenzia Nazionale per la Sicurezza Ferroviaria) on all rail infrastructure where a train protection system is not operational. The measure was taken in 2016 after a train collision happened in northern Puglia that caused 23 deaths. ANSF Circolare 009956/2016.

2 Please see the introduction to this volume regarding the contextualisation and methodology of this research.

\section{References}

Agenzia Nazionale per la Sicurezza Ferroviaria. 2016. "Pubblicata la nota ANSF 009956/2016 del 26 settembre 2016 relativa ai Provvedimenti urgenti in materia di sicurezza dell'esercizio ferroviario sulle reti regionali di cui al decreto 5 Agosto 2016 del Ministro delle Infrastrutture e dei trasporti 'Individuazione delle reti ferroviarie rientranti nell'ambito di applicazione del decreto legislativo 15 Luglio 2015, $\mathrm{N}^{\circ} 112$ per le quali sono attribuite alle Regioni le funzioni e i compiti di programmazione e di amministrazione"”. https://www.ansf.gov. it/documents/20142/241502/0099562016_260916.pdf/66f36027-5d40-2b4b-902d38408d6f8612?version=1.0\&download=true. Accessed 19 September 2020.

Automobile Club d'Italia. 2018. ACI Autoritratto. http://www.aci.it/laci/studi-ericerche/dati-e-statistiche/autoritratto.html. Accessed 12 December 2019.

Capestro, Mauro, Elisabetta Tarantino, Fabrizio Morgagni, Eleonora Tricarico, and Gianluigi Guido. 2014. "Distretti calzaturieri in crisi: cause del declino e 
strategie di rinnovamento.” In Economia e Società Regionale 1: 187-212. https:// doi.org/10.3280/ES2014-001015.

FS News. 2019. "Affidati i lavori per l'elettrificazione della linea Martina FrancaGagliano del Capo.” 31 July 2019. http://www.fsnews.it/fsn/Gruppo-FS-Italiane/ Altre-societ $\% \mathrm{C} 3 \% \mathrm{~A} 0 /$ Ferrovie-del-Sud-Est-affidati-i-lavori-per-elettrificazionedella-linea-Martina-Franca-Gagliano-del-Capo. Accessed 12 December 2019.

Istituto Nazionale di Statistica. 2018a. I.Stat. http://dati.istat.it/. Accessed 12 December 2018.

Istituto Nazionale di Statistica. 2018b. 8milaCensus. http://ottomilacensus.istat.it/. Accessed 12 December 2018.

Regione Puglia - Area Interna Sud Salento. 2018. Documento di Strategia approvato. http://old2018.agenziacoesione.gov.it/it/arint/Strategie_di_area/Strategie_ di_area.html. Accessed 12 December 2019.

Regione Puglia - Assessorato al Welfare, Unità Referente Pari opportunità e non discriminazione. 2018. "I Piani dei Tempi e degli Spazi." http://www.pari opportunita.regione.puglia.it/piani-dei-temi-e-degli-spazi. Accessed 12 December 2019.

Regione Puglia - ASSET. 2019. "Indagine sulla mobilità dei cittadini residenti nel territorio regionale finalizzata allo studio della domanda di trasporto in Puglia." http://asset.regione.puglia.it/?mobilita-indagine. Accessed 12 December 2019.

Urso, Giulia, Marco Modica, and Alessandra Faggian. 2019. "Resilience and sectoral composition change of Italian inner areas in response to the great recession.” In Sustainability 11, no. 9: 2679. https://doi.org/10.3390/su11092679. 